\title{
Very Simple Mathematical Model of MMT (Modern Monetary Theory)
}

\author{
Yasuhito Tanaka \\ Faculty of Economics, Doshisha University, Kamigyo-ku, Kyoto, 602-8580, Japan \\ E-mail: yatanaka@mail.doshisha.ac.jp
}

Received: August 13, 2021 Accepted: September 1, 2021 Published: September 4, 2021

doi:10.5296/ber.v11i3.18983ＵRL: https://doi.org/10.5296/ber.v11i3.18983

\begin{abstract}
The purpose of this paper is to provide a concise theoretical and mathematical foundation for the major parts of the debate in the recently discussed school of economics called Modern Monetary Theory (MMT), while maintaining the basics of the neoclassical microeconomic framework, such as utility maximization of consumers using budget constraints and utility functions, and equilibrium of demand and supply of goods under perfect competition with constant returns to scale technology. By a two-periods overlapping generations (OLG) model in which the economy grows by technological progress, we will show that: 1) We need a budget deficit to achieve full employment with constant price when the economy grows by technological progress. This budget deficit should not be offset by future surplus; 2) A budget deficit that exceeds the level necessary to maintain full employment in a growing economy with constant price will cause inflation. A stable budget deficit is required to prevent further inflation; 3) A budget deficit that is insufficient to maintain full employment will cause a recession with involuntary unemployment. A budget deficit larger than the one necessary and sufficient to maintain full employment without a recession can overcome a recession caused by insufficient budget deficit and restore full employment. The deficit created to overcome the recession should not be offset by subsequent surpluses, since full employment can then be maintained through constant budget deficits.
\end{abstract}

Keywords: MMT, Economic growth, Budget deficit, Inflation

\section{Introduction}

For example, Japan's outstanding government debt exceeds 1,100 trillion yen, and it is said to be in a critical situation. On the other hand, there are those who believe that there is no problem in accumulating budget deficits as long as they are not debts to foreign countries and that fiscal policy should be evaluated only in terms of its effectiveness in preventing inflation and achieving full employment and stable economic growth. One such theory is the so-called 
Functional Finance Theory of Lerner $(1943,1944)$, a famous economist.

In recent years, MMT (Modern Monetary Theory, Wray (2015), Mitchell, Wray and Watts (2019), Kelton (2020)), which has become popular in the U.S. and also in Japan, is a typical example. The MMT proponents themselves admit that Lerner's theory is the source of their thinking. However, it is often pointed out that in contrast to mainstream economics, which is based on the neoclassical framework, MMT does not often use mathematical and theoretical models for analysis ${ }^{1}$.

In this paper, while maintaining the basics of the neoclassical microeconomic framework, such as utility maximization of consumers through utility functions and budget constraints, and equilibrium of supply and demand of goods under perfect competition with constant returns to scale technology, the idea of the effect of fiscal policy, which is the backbone of functional finance theory and MMT discussions, is actively discussed using a very simple mathematical model.

We will prove the following.

1) We need a budget deficit to achieve full employment with constant price when the economy grows by technological progress. The budget deficit provides the increase in the savings by consumers. Because we need budget deficit for economic growth, this budget deficit should not be offset by future surplus. (Section 2)

2) A budget deficit that exceeds the level necessary to maintain full employment in a growing economy with constant price will cause inflation. A stable budget deficit is required to prevent further inflation. (Section 3)

3) A budget deficit that is insufficient to maintain full employment will cause a recession with involuntary unemployment. (Section 4)

A budget deficit larger than the one necessary and sufficient to maintain full employment without a recession can overcome a recession caused by insufficient budget deficit and restore full employment.

The deficit created to overcome the recession should not be offset by subsequent surpluses, since full employment can then be maintained through constant budget deficits.

We consider restoration of full employment by fiscal spending (Section 5) and tax reduction (Section 6 and 7).

Fiscal spending has a role to increase the demand for goods, on the other hand taxes reduce the demand for goods by reducing people's disposable income. A balance between fiscal spending and taxes is important to achieve full employment with stable growth while preventing inflation.

\footnotetext{
${ }^{1}$ Other references are Mochizuki (2020), Morinaga (2020) and Park (2020). These are introductory texts of MMT written in Japanese.
} 


\section{Economic Growth and Budget Deficit}

We use a two-periods overlapping generations (OLG) model which is a simplified version of the model used by Otaki $(2007,2009,2015)$. We assume that the good is produced under perfect competition although Otaki considered monopolistic competition. Consumers live over two-periods, the younger period and the older period. They work only in the younger period. In the older period they consume the good by their savings carried over from their younger period. The ratio of consumption of the consumers in the younger period is $\alpha$, and that in the older period is $1-\alpha$. We assume $\frac{1}{2}<\alpha<1$. $\alpha$ is the marginal propensity to consume. These values are obtained by utility maximization of consumers by the Cobb-Douglas utility function about consumptions in the younger period and the older period.

There is one good produced under perfect competition with constant returns to scale technology. The labor productivity and the nominal wage rate in a period (Period 1) is one. The economy grows by technological progress. The labor productivity increases at the rate $\gamma-1>0$ from period to period. The nominal wage rate also increases at the rate $\gamma-1$ with constant price. We suppose full employment in this section. Let $G$ and $T$ be the government expenditure (or the fiscal spending) and the tax in Period 1. $L_{f}$ is the labor supply, or employment in a full employment state. The savings of the younger generation consumers in Period 1 is

$$
(1-\alpha)\left(L_{f}-T\right)
$$

This is equal to the consumption of the older generation consumers in Period 2. The government expenditure and the tax in Period 2 are $\gamma G$ and $\gamma T$. The consumption of the younger generation consumers in Period 2 is

$$
\alpha \gamma\left(L_{f}-T\right) .
$$

The total supply in Period 2 is

$$
\gamma L_{f}
$$

The total demand is

$$
\alpha \gamma\left(L_{f}-T\right)+(1-\alpha)\left(L_{f}-T\right)+\gamma G .
$$

From the equilibrium between the total supply and the total demand, we get

$$
\gamma L_{f}=\alpha \gamma\left(L_{f}-T\right)+(1-\alpha)\left(L_{f}-T\right)+\gamma G .
$$

Then,

$$
\gamma(G-T)=\gamma(1-\alpha)\left(L_{f}-T\right)-(1-\alpha)\left(L_{f}-T\right)=(\gamma-1)(1-\alpha)\left(L_{f}-T\right) .
$$

This implies 
budget deficit $=$ savings by the younger generation consumers

- savings by the older generation consumers.

If $\gamma=1$, budget deficit $=0$.

If savings earn interest at the rate $r$, and the government pays it, then (1) is

$$
\gamma L_{f}=\alpha \gamma\left(L_{f}-T\right)+(1-\alpha)(1+r)\left(L_{f}-T\right)+\gamma G,
$$

and we have

$$
\begin{gathered}
\gamma(G-T)+(1-\alpha) r\left(L_{f}-T\right)=\gamma(1-\alpha)\left(L_{f}-T\right)-(1-\alpha)\left(L_{f}-T\right) \\
=(\gamma-1)(1-\alpha)\left(L_{f}-T\right) .
\end{gathered}
$$

This means

budget deficit including payment of interest

$=$ savings by the younger generation consumers

- savings by the older generation consumers.

Summarizing the results, we obtain

Proposition 1 We need a budget deficit to achieve full employment with constant price when the economy grows by technological progress.

The budget deficit provides the increase in the savings by consumers. Because we need budget deficit for economic growth, this budget deficit should not be offset by future surplus.

\section{Inflation by Excess Budget Deficit}

Let $p$ be the price and the nominal wage rate in Period 2, the government expenditure be $\zeta G$. We assume that the nominal value of the tax is $\gamma T$. The nominal total supply in Period 2 is

$$
p \gamma L_{f} .
$$

The nominal total demand is

$$
\alpha \gamma\left(p L_{f}-T\right)+(1-\alpha)\left(L_{f}-T\right)+\zeta G .
$$

From the equilibrium between them, we obtain

$$
p \gamma L_{f}=\alpha \gamma\left(p L_{f}-T\right)+(1-\alpha)\left(L_{f}-T\right)+\zeta G,
$$

and then

$$
\zeta G-\gamma T=(1-\alpha) \gamma\left(p L_{f}-T\right)-(1-\alpha)\left(L_{f}-T\right) .
$$

Comparing this with (2),

$$
(\zeta G-\gamma T)-\gamma(G-T)=(1-\alpha)\left[\gamma\left(p L_{f}-T\right)-\gamma\left(L_{f}-T\right)\right] .
$$

This is rewritten as 


$$
(\zeta-\gamma) G=(1-\alpha)(p-1) \gamma L_{f} .
$$

When $(\zeta G-\gamma T)-\gamma(G-T)=(\zeta-\gamma) G>0$, we have $p>1$. Summarizing the results in the following proposition,

Proposition 2 A budget deficit (given $\operatorname{tax}^{2}$ ) that exceeds the level necessary to maintain full employment in a growing economy with constant price will cause inflation.

\section{Recession and Involuntary Unemployment by Insufficient Budget Deficit}

Let $L$ be the employment in Period 2. Assume that the government expenditure is $\zeta G$, the tax is $\gamma T$, and $p=1$. The nominal total supply in Period 2 is

$$
\gamma L
$$

The nominal total demand is

$$
\alpha \gamma(L-T)+(1-\alpha)\left(L_{f}-T\right)+\zeta G .
$$

From the equilibrium between them, we obtain

$$
\gamma L=\alpha \gamma(L-T)+(1-\alpha)\left(L_{f}-T\right)+\zeta G
$$

and then

$$
\zeta G-\gamma T=(1-\alpha) \gamma(L-T)-(1-\alpha)\left(L_{f}-T\right)
$$

Comparing this with (2),

$$
(\zeta G-\gamma T)-\gamma(G-T)=(1-\alpha)\left[\gamma(L-T)-\gamma\left(L_{f}-T\right)\right]=(1-\alpha) \gamma\left(L-L_{f}\right) .
$$

When $(\zeta G-\gamma T)-\gamma(G-T)<0, L<L_{f}$ is derived. Then, there is involuntary unemployment $^{3}$. Summarizing the results, we obtain

Proposition 3 A budget deficit (given $\operatorname{tax}^{4}$ ) that is insufficient to maintain full employment will cause a recession with involuntary unemployment.

\section{Recovery from Recession by the Government Expenditure}

We will recover full employment in Period 3. Suppose that the taxes in Period 2 and 3 are $\gamma T$ and $\gamma^{2} T$. The total supply is

$$
\gamma^{2} L_{f}
$$

\footnotetext{
2 A change in fiscal spending and that in tax have different effects on the national income. An increase in fiscal spending and tax while keeping the budget deficit constant will lead to inflation, while a decrease in fiscal spending and tax while keeping the budget deficit constant will lead to a recession. It is because the multiplier of a change in tax is smaller than that of a change in fiscal spending. On the other hand, a change in tax has an effect on consumption of the older generation consumers in the next period. The analyses in Section 6 and 7 are related to this point.

3 About involuntary unemployment please see Hattori and Tanaka (2020).

${ }^{4}$ Please see footnote 2.
} 
The consumption (or the savings) of the older generation consumers is

$$
(1-\alpha) \gamma(L-T)
$$

The consumption of the younger generation consumers is

$$
\alpha \gamma^{2}\left(L_{f}-T\right) .
$$

Let $\zeta G$ be the government expenditure. The total demand is

$$
\alpha \gamma^{2}\left(L_{f}-T\right)+(1-\alpha) \gamma(L-T)+\zeta G .
$$

Note that $L$ is employment in Period 2.

From the equilibrium between the total supply and the total demand, we have

$$
\gamma^{2} L_{f}=\alpha \gamma^{2}\left(L_{f}-T\right)+(1-\alpha) \gamma(L-T)+\zeta G .
$$

On the other hand, if there is no recession, in Period 3 (1) means

$$
\gamma^{2} L_{f}=\alpha \gamma^{2}\left(L_{f}-T\right)+(1-\alpha) \gamma\left(L_{f}-T\right)+\gamma^{2} G .
$$

By (5) and (6),

$$
\zeta G-\gamma^{2} G=(1-\alpha) \gamma\left(L_{f}-L\right)
$$

When $L<L_{f}$, we have $\zeta>\gamma^{2}$. Therefore, a larger budget deficit is required than would be required to maintain full employment in the absence of a recession. We summarize the results in the following proposition.

Proposition 4 A budget deficit larger than the one necessary and sufficient to maintain full employment without a recession can overcome a recession caused by insufficient budget deficit and restore full employment.

The deficit created to overcome the recession should not be offset by subsequent surpluses, since full employment can then be maintained through constant budget deficits.

\section{Recovery from Recession by the Tax Reduction}

Again we will recover full employment in Period 3. Suppose that the government expenditures in Period 2 and 3 are $\gamma G$ and $\gamma^{2} G$.

The total supply is

$$
\gamma^{2} L_{f}
$$

The consumption (or the savings) of the older generation consumers is

$$
(1-\alpha) \gamma(L-T)
$$

Let $\eta T$ be the tax in Period 3. Then, the consumption of the younger generation consumers is

$$
\alpha\left(\gamma^{2} L_{f}-\eta T\right)
$$


The total demand is

$$
\alpha\left(\gamma^{2} L_{f}-\eta T\right)+(1-\alpha) \gamma(L-T)+\gamma^{2} G .
$$

Note that $L$ is employment in Period 2.

From the equilibrium between the total supply and the total demand, we have

$$
\gamma^{2} L_{f}=\alpha\left(\gamma^{2} L_{f}-\eta T\right)+(1-\alpha) \gamma(L-T)+\gamma^{2} G .
$$

Again if there is no recession, (6) holds in Period 3. By (6) and (8),

$$
\alpha\left(\gamma^{2}-\eta\right) T=(1-\alpha) \gamma\left(L_{f}-L\right)
$$

When $L<L_{f}$, we get $\eta<\gamma^{2}$.

\section{Complexity of Tax Reduction Policy}

Suppose that there were recession and involuntary unemployment in Period 2, and we have recovered full employment in Period 3 by tax reduction policy. In the next Period 4 the consumption of the older generation consumers is

$$
(1-\alpha)\left(\gamma^{2} L_{f}-\eta T\right)
$$

Let $\gamma^{3} G$ and $\eta_{2} T$ be the government expenditure and the tax in this period. The consumption of the younger generation consumers is

$$
\alpha\left(\gamma^{3} L_{f}-\eta_{2} T\right)
$$

The total demand is

$$
\alpha\left(\gamma^{3} L_{f}-\eta_{2} T\right)+(1-\alpha)\left(\gamma^{2} L_{f}-\eta T\right)+\gamma^{3} G
$$

The total supply is

$$
\gamma^{3} L_{f}
$$

From the equilibrium between the total supply and the total demand, we have

$$
\gamma^{3} L_{f}=\alpha\left(\gamma^{3} L_{f}-\eta_{2} T\right)+(1-\alpha)\left(\gamma^{2} L_{f}-\eta T\right)+\gamma^{3} G
$$

If there is no recession,

$$
\gamma^{3} L_{f}=\alpha \gamma^{3}\left(L_{f}-T\right)+(1-\alpha) \gamma^{2}\left(L_{f}-T\right)+\gamma^{3} G
$$

holds. By (10) and (11),

$$
\alpha\left(\eta_{2}-\gamma^{3}\right) T=(1-\alpha)\left(\gamma^{2}-\eta\right) T .
$$

When $\eta<\gamma^{2}$, we have $\eta_{2}>\gamma^{3}$. Thus, we need tax increase in Period 4 .

Let the tax in Period 5 be $\eta_{3} T$. Inductively, the following equation can be obtained.

$$
\alpha\left(\eta_{3}-\gamma^{4}\right) T=(1-\alpha)\left(\gamma^{3}-\eta_{2}\right) T .
$$


Let the tax in Period $n+2$ be $\eta_{n} T$. Generally, we obtain

$$
\alpha\left(\eta_{n}-\gamma^{n+1}\right) T=(1-\alpha)\left(\gamma^{n}-\eta_{n-1}\right) T,
$$

or

$$
\left(\eta_{n}-\gamma^{n+1}\right) T=-\frac{1-\alpha}{\alpha}\left(\eta_{n-1}-\gamma^{n}\right) T
$$

This means that $\left(\eta_{n}-\gamma^{n+1}\right) T$ is a geometric progression whose common ratio is $-\frac{1-\alpha}{\alpha}$.

Let $\eta_{1}=\eta$. Each term of this geometric progression represents the difference between the level of taxation when the tax is reduced in Period 3 as a countermeasure to a recession, and full employment is maintained thereafter, and the level of taxation when full employment is maintained continuously without a recession. After $n=1$ (Period 3) these values are positive, negative, positive, negative, ...., and so on. The sum of the geometric progression from 1 to $n$ is

$$
S=\sum_{i=1}^{n}\left(\eta_{i}-\gamma^{i+1}\right) T=\frac{1-\left(-\frac{1-\alpha}{\alpha}\right)^{n}}{1+\frac{1-\alpha}{\alpha}}\left(\eta-\gamma^{2}\right) T=\alpha\left[1-\left(-\frac{1-\alpha}{\alpha}\right)^{n}\right]\left(\eta-\gamma^{2}\right) T .
$$

Assume $\frac{1}{2}<\alpha<1$. When $n \rightarrow \infty,\left(-\frac{1-\alpha}{\alpha}\right)^{n} \rightarrow 0$, and

$$
S \rightarrow \alpha\left(\eta-\gamma^{2}\right) T
$$

From (9) this is equal to the minus of (7).

Comparing tax cuts and fiscal spending to overcome recessions, the magnitude of the first tax cut, $\left(\eta-\gamma^{2}\right) T$, is larger than the additional fiscal spending represented in (7). However, the magnitude of the sum of the first tax cut plus subsequent tax increases and decreases to infinity is equal to the additional fiscal spending.

But, convergence does not occur unless the marginal propensity to consume $\alpha$ is greater than $1 / 2$.

We have shown the following result.

Proposition 5 We can restore full employment from a recession by tax reduction policy. The magnitude of the first tax cut is larger than the additional fiscal spending to restore full employment. However, the magnitude of the sum of the first tax cut plus subsequent tax increases and decreases to infinity is equal to the additional fiscal spending.

\section{Concluding Remark}

By a two-periods overlapping generations (OLG) model with production of the good under perfect competition, we have shown that excessive budget deficits lead to inflation, but budget deficits are necessary and useful for economic growth and overcoming recessions.

Please note that fiscal spending has a role to increase the demand for goods, on the other hand 
taxes reduce the demand for goods by reducing people's disposable income. A balance between fiscal spending and taxes is important to achieve full employment with stable growth while preventing inflation.

We have used a simple two-periods overlapping generations model. We can generalize the arguments in this paper by a three-periods or three generations overlapping generations model which includes a childhood period. It is currently under study.

\section{Acknowledgement}

I appreciate the valuable comments and suggestions by the editor and the reviewers which substantially improved the paper. This work was supported by the Japan Society for the Promotion of Science KAKENHI (Grant Number 18K01594).

\section{References}

Hattori, M., \& Tanaka, Y. (2020). Divisibility of labor supply and involuntary unemployment: a perfect competition model. Journal of Economics and Management, 16, 193-206. [Online] Available: https://jem.fcu.edu.tw/assets/jem/past_issues/vol.16_no.2/PDF/vol.16_no.2_05.pdf

Kelton, S. (2020). The Deficit Myth: Modern Monetary Theory and the Birth of the People's Economy. Public Affairs.

Lerner, A. P. (1943). Functional finance and the federal debt. Social Research, 10, 38-51.

Lerner, A. P. (1944). The Economics of Control: Principles of Welfare Economics. Macmillan.

Mitchell, W., Wray, L. R., \& Watts, M. (2019). Macroeconomics. Red Globe Press.

Mochizuki, S. (2020). A book understanding MMT (in Japanese, MMT ga yokuwakaru hon). Shuwa System.

Morinaga, K. (2020). MMT will save Japan (in Japanese, MMT ga nihon wo sukuu). Takarajimasha.

Otaki, M. (2007). The dynamically extended Keynesian cross and the welfare-improving fiscal policy. Economics Letters, 96, 23-29. https://doi.org/10.1016/j.econlet.2006.12.005

Otaki, M. (2009). A welfare economics foundation for the full-employment policy. Economics Letters, 102, 1-3. https://doi.org/10.1016/j.econlet.2008.08.003

Otaki, M. (2015). Keynesian Economics and Price Theory: Re-orientation of a Theory of Monetary Economy. Springer. https://doi.org/10.1007/978-4-431-55345-8

Park, S. (2020). The fallacy of fiscal collapse (in Japanese, Zaisei hatanron no ayamari). Seitosha.

Wray, L. R. (2015). Modern Money Theory: A Primer on Macroeconomics for Sovereign Monetary Systems (2nd ed.). Palgrave Macmillan. 


\section{Copyright Disclaimer}

Copyright for this article is retained by the author(s), with first publication rights granted to the journal.

This is an open-access article distributed under the terms and conditions of the Creative Commons Attribution license (http://creativecommons.org/licenses/by/4.0/). 